\title{
THE STRUCTURE OF ENVIRONMENTAL CONCERN: CONCERN FOR SELF, OTHER PEOPLE, AND THE BIOSPHERE
}

P. Wesley Schultz, California State University, San Marcos, U.S.A.

\begin{abstract}
Four studies are reported on the structure of environmental attitudes. Based on Stern \& Dietz' (1994) value- basis theory for environmental attitudes, we predicted that concerns for environmental issues would form three correlated factors. The first study presents the results from a confirmatory factor analysis of the proposed three-factor model among a sample of 1010 U.S. college students. The second study presents the results from a telephone survey of 1005 U.S. respondents. The third study examines the relationship between the three identified types of environmental concerns, existing measures of environmental attitudes, empathy, and social- value orientation. The final study presents the results from a multi-group confirmatory factor analysis examining the factor structure of environmental concerns among college students in ten countries. Additional analyses are provided on the relationship between values and environmental concerns. Taken together, the results provide strong evidence for the distinction between egoistic, altruistic, and biospheric environmental concerns.
\end{abstract}


In increasing numbers, people around the world are expressing concern for environmental issues. National surveys conducted in the U.S. and internationally have found high percentages of respondents who list environmental problems as foremost among social problems (Dunlap, 1991; Dun- lap et al., 1993; Bosso, 1994; Kempton et al., 1995). Indeed, it is difficult today to find someone who is openly anti-environmental. In this paper, we distinguish between different types of environmental attitudes that are oriented around three sets of valued objects: self, other people, and the biosphere.

In nearly 30 years worth of published psychological research on environmental attitudes, a variety of scales have been developed that measure an individual's degree of concern for humancaused environ- mental problems (Weigel, 1983). The 1970s saw a spate of scales designed to measure general concern for and knowledge about environmental issues. Scales were developed by Weigel and Weigel (1978), Lounsbury and Tornatzky (1977), Maloney and Ward (1973), Maloney et al. (1975), and Dunlap and Van Liere (1978). Since the early 1980s, research on the measurement of environmental concern has slowed considerably. This is undoubtedly due to some of the limitations uncovered by researchers using the published scales, as well as to fluctuations in areas of research activity. A variety of criticisms have been leveled at the available scales, including low correlations with proenvironmental behavior, low reliabilities, inconsistencies across measures, and lack of an integrating theoretical perspective (Dun- lap et al., 2000; Heberlein, 1981; Olsen, 1981; Stern et al., 1995b; Stern \& Oskamp, 1987).

Recent theoretical developments (cf., Bragg, 1996; Schultz \& Zelezny, 1999; Stern \& Dietz, 1994; Stern et al., 1993; Stern et al., 1995b; Thompson \& Barton, 1994; Weigert, 1997) suggest new, and potentially more profitable, lines of research for the study of environmental attitudes. Stern and Dietz (1994) argue that attitudes of concern about environmental is- sues are based on a person's more general set of values. That is, attitudes about environmental issues are based on the relative importance that a person places on themselves, other people, or plants and animals which Stern and Dietz (1994) labeled egoistic, social-altruistic, and biospheric. The value-basis theory is an extension of Schwartz's (1977) norm-activation model of altruism, and suggests that concerns about specific environmental issues are due to an awareness of harmful consequences of environmental problems to a value or valued object.

Despite the intuitive appeal of this value-basis theory, there is little supporting evidence. Stern et al. (1995) used Schwartz's (1992, 1994) value items to assess a person's value orientation. Seeking evidence for the existence of the three value-bases for environmental attitudes, Stern et al. (1995b) con- ducted telephone interviews with randomly selected adults. They measured the biospheric value orientation with items selected from Schwartz's $(1992,1994)$ self-transcendence scale, the social-altruistic value orientation with separate items from Schwartz's selftranscendence scale, and the egoistic value orientation with items from Schwartz's selfenhancement scale. The results from a factor analysis of the value items revealed a two-factor structure in which eogistic values comprised the first factor, and both biospheric and socialaltruistic values comprised the second. Based on these results, Stern et al. (1995b) concluded that 'the biospheric value orientation that appears in the literature on environ- mentalism cannot yet be differentiated from a more generalized self-transcendent value cluster' (p. 1630). Despite the lack of evidence indicating three distinct value orientations, it is possible that more specific attitudes of environmental concern may still be organized around distinct valued objects, even though the underlying values may be similar. In- deed, social psychological research on values suggests that attitudes are often associated with multiple, and even contradictory, values (Eagly \& Chaiken, 1993). Similarly, distinct value orientations do not necessitate distinct attitudes. Perhaps it is the case that different value orientations predict a general, unidimensional concern for the harmful consequences of environmental problems.

In previous research, we have worked to assess the structure of environmental attitudes (Schultz, 2000). By coding open-ended responses to the question 'What is the environmental problem that concerns you the most and why?’ we were able to identify three clusters of environmental attitudes 
which represent egoistic, altruistic, and biospheric concerns. Analyses showed that concerns for self (my health, my future, my lifestyle, me), other people (people in my community, all people, children, my children), and the biosphere (plants, animals, marine life, birds) loaded on separate, but correlated, factors. However, the participants in this study were college students, and it is unclear if the three factor-structure would generalize to other college students in the U.S., the general population, or people in other countries. In addition, the relationships between egoistic, altruistic, and biospheric concerns with other existing measures of environmental attitudes, and with measures of values, has yet to be reported.

In this paper, we tested the proposed three-factor model for environmental concern by assessing the importance of valued objects organized around self, other people, and all living things. The first study presents the results from a confirmatory factor analysis of the proposed three-factor model among a sample of 1010 U.S. college students. The second study presents the results from a confirmatory factor analysis of environmental concerns among respondents to a telephone survey. The third study examines the relationship between these environ- mental concerns, existing measures of environmental attitudes, empathy, and social-value orientation. The final study presents the results from a multi- group confirmatory factor analysis examining the factor structure of environmental concerns among respondents from Colombia, Costa Rica, the Dominican Republic, Ecuador, El Salvador, Panama, Paraguay, Peru, Spain, and Venezuela. Additional analyses are provided on the relationship between values and environmental concern.

\section{Study 1}

The goal of this first study was to confirm a set of items that would assess each of the three sets of valued objects (self, others, biosphere) related to environmental concern. We sought to assess attitudes of environmental concern, and not values (which we view as more general determinants of these attitudes).

\section{Methodology}

Sample. Participants in the study were 1010 psychology undergraduates from several large universities in the United States.

Materials. Attitudes of environmental concern were assessed using items adopted from our previous research. Participants were asked to rate 12 items: marine life, birds, animals, plants, my health, my future, my lifestyle, me, children, people in my country, all people, and my children (in a randomized order). The question was embedded within a larger paper-and-pencil questionnaire about a variety of social issues. The exact question wording in shown in Appendix 1.

Statistical Analysis. A confirmatory factor analysis (CFA) was performed using AMOS 3.6 (Arbuckle, 1997). Missing values were replaced with series means. For a more detailed description of CFA see Bollen (1989), Gorsuch (1983), Kaplan (2000), or Maruyama (1998). A critical issue in CFA is the assessment of the degree to which the data fit the model. A variety of fit indices have been developed, but there is no consensus among statisticians about the criteria required to demonstrate a reasonable fit. Of the measures of fit developed to test a priori models, the chisquare statistic is by far the most commonly reported. Chi-square tests the extent to which the proposed model reproduces exactly the observed matrix. However, because of the limitations with chi-square (Bentler, 1990; Cudeck \& Browne, 1983), researchers have come to rely on a variety of other fit indices. In the present study, we selected three other widely used indices: The good- ness of fit index (GFI), the root mean square error of approximation (RMSEA), and the Tucker-Lewis 
index (TLI). GFIs and TLIs of 0-90 or greater are typically interpreted as indicating an 'acceptable' fit, as are RMSEAs of 0-10 or less.

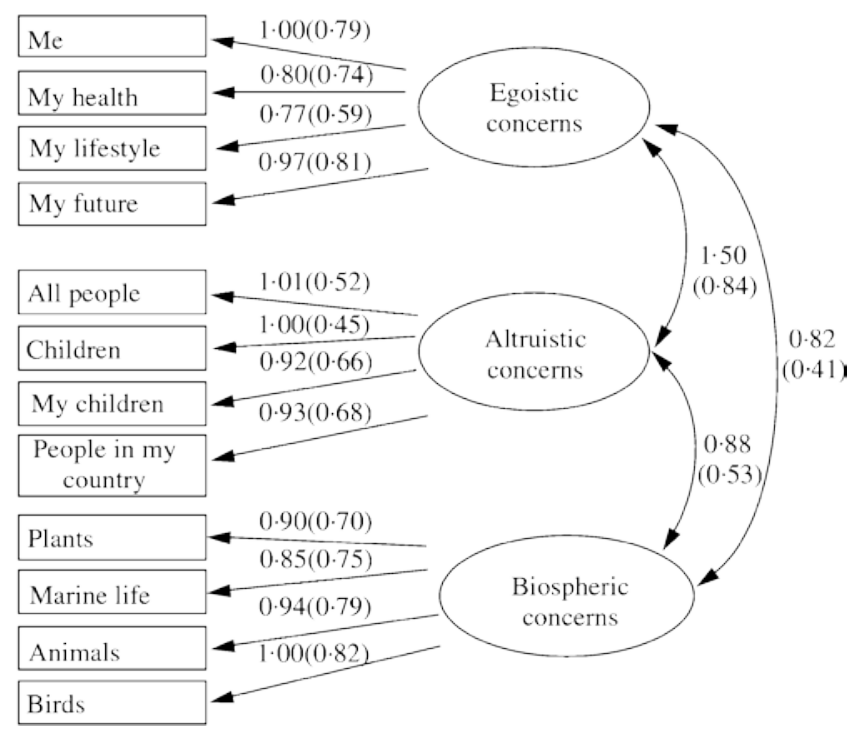

FIGURE 1. Results from a Confirmatory Factor Analysis with a Sample of 1,010 U.S. College Students.

\section{Results}

The CFA tested three possible models: A one-factor, a two-factor, and a three-factor model. The one-factor model is consistent with the view of environmental concern as a unidimensional construct ranging from unconcerned at the low end, to concerned at the high end. In this model, all 12 items load on a single factor. This is the implicit model adopted in much of the research on attitudes of environmental concern. In the two-factor model, the four biospheric items (animals, plants, marine life, birds) load on one factor, while the remaining eight items (my children, people in my country, all people, children, my health, my future, my lifestyle, and me) load on a second factor. This two-factor model is consistent with Thompson and Barton's (1994) classification of environmental attitudes as either rooted in a concern for all living things or in a concern for humans (self-included). The three factor model is consistent with Stern and Dietz's (1994) tripartite conceptualization of environmental concerns grounded in clusters of valued objects.

Results from the Confirmatory Factor Analysis indicated that the independence model could be rejected (df. $=66 ; \chi^{2}=4709-04 ; \chi^{2} / \mathrm{df} .=71-35 ; \mathrm{RMSEA}=0-26 ;$ GFI $=0-41 ;$ AGFI $=0-31 ; \mathrm{TLI}=$ $0-00)$. The one-factor showed an improved, but still unacceptable fit (df. $=54 ; \chi^{2}=1577-16 ; \chi^{2} / \mathrm{df}$. = 29-21; RMSEA $=0$ 17; GFI $=0$ 73; AGFI $=0$ 62; TLI = 0 59). The two-factor model was significantly better $\left(\chi^{2}(1)=1163-04 ; p<0-001\right)$ than the one-factor model $\left(\mathrm{df} .=53 ; \chi^{2}=414-12\right.$; $\chi^{2} /$ df. $=7-82$; RMSEA $=0-10$; GFI = 0-92; AGFI = 0-89; TLI =0-88.) The three-factor model showed a significant $\left(\chi^{2}(2)=99-37 ; p<0-001\right)$ improvement over the 2 -factor model, and an overall acceptable fit (df. $=51 ; \chi^{2}=31475 ; \chi^{2} / \mathrm{df} .=6-17 ; \mathrm{RMSEA}=0-07 ; \quad$ GFI = 0-95; AGFI 0-92; TLI = 0-93). The unstandardized factor weights, standardized factor weights (shown in parentheses), and the un- standardized and standardized (shown in parentheses) phi coefficients between the three factors are presented in Figure 1.

Scale scores for each of the factors were generated by averaging the items. Alpha reliability for the four egoistic items was 0-71, for altruistic items alpha was 0-64, and for biospheric items alpha was 0-86. Average scores for the three factors were: egoistic concerns $M=5-47$ (S.D. = 151), altruistic concerns $M=5-78$ (S.D. = 1-49), and biospheric concerns $M=5-33$ (S.D. = 1-38). 


\section{Study 2}

The results from the first study provided evidence for a three-factor model of environmental concern among college students. However, to what extent would the same factor structure be found in a sample of the general public? Indeed, given Stern et al's(1995b) findings in their telephone survey, it would seem that the ways in which college students think about environmental issues may be different from the ways in which the general public thinks about environmental issues. To address this question, a telephone survey was conducted using a randomdigit dialing technique.

\section{Methodology}

Sample. The survey was completed by a sample of 1005 California adults. The sample was obtained using a random digit dialing method, which gives all households with telephones (including those with listed and unlisted numbers) an equal chance of being selected for the survey.

Of the 1005 respondents, 49 per cent were female and 51 per cent were male. The ethnic breakdown showed 64 per cent were non Hispanic White, 22 per cent were Latino, 6 per cent were Black, and 7 per cent were other. Average age was 45, with a range from 18 to 89. Average income range was $\$ 40 \mathrm{~K}-60 \mathrm{~K}$. A breakdown of political party showed 52 per cent were Democrat, 30 per cent were Republican, and 18 per cent were other. Average education level was 'Some College.'

Materials. The survey contained measures of demo- graphics, public opinion poll items, and a modified version of the environmental concern question used in the previous study (see Appendix 1). Question wording and items were modified slightly to accommodate the telephone administration. The initial item read:

People often express concern about environmental problems, but some people differ as to which consequences concern them the most. I am going to read some different areas where environmental problems could have harmful consequences, and for each please rate how concerned you are about their impact using a scale from 1 to 7 . If you are not at all concerned, give it a rating of 1 . If you are extremely concerned, give it a rating of 7. Of course, you can choose any number between 1 and 7 for your answer.

The items were: marine life, plants, animals, birds, children, people in the United States, the human race, people in your community, your health, your future, your lifestyle, and your prosperity. The items were administered in random order.

\section{Results}

Responses to the 12 items were analysed using confirmatory factor analysis of covariance matrices. Three successive models were fit to the data. Results showed that the one-factor model could be rejected (df. $=54 ; \chi^{2}=1369-10 ; \chi^{2} / \mathrm{df} .=25-35 ;$ RMSEA $=0-16 ; \quad$ GFI $=0-76$; AGFI $=0-65 ; \quad T L I=0-82$ ). The two-factor model, in which the egoistic and altruistic items load on a single factor and biospheric items on a second, was significantly better $\left(\chi^{2}(1)=91330\right.$; $p<0$ 001) than the one-factor model (df. $=53 ; \chi^{2}=45580 ; \chi^{2} / \mathrm{df} .=860$; RMSEA $=009$; GFI $=$ 0 92; AGFI 0 89; TLI =0 94). Overall, the two-factor model showed a reasonable level of fit. However, because of our a priori expectation, we proceeded to test the three-factor model. The results showed that the three factor model provided a significantly better fit to the data than the two-factor model $\left(\chi^{2}(2)=115-26 ; p<0-001\right)$. The fit indices for the three-factor model were $\left(\chi^{2}\right.$ $(51)=340-54 ;$ RMSEA = 0-07; GFI = 0-95; AGFI = 0-92; TLI = 0-96). 
Factor weights and phi coefficients between factors were similar to those identified in Study 1 and shown in Figure 1.

Scores for the three environmental concern scales were produced by averaging the items. Alpha reliability for the three scales were: Egoistic concerns 0-88, altruistic concerns 0-90, biospheric concerns, 0-90. Average scores for the scales were: egoistic concerns $M=5-48$ (S.D. = 1-55), altruistic concerns $M=5-84$ (S.D. = 1-43), biospheric concerns $M=5-46$ (S.D. = 1-49). Note that these scores are very similar to those obtained for college students in Study 1 . The only appreciable difference is for biospheric concerns, where college students scored slightly lower ( $M$ = 5-33) than this sample of the general public $(M=5-46)$.

Demographic Correlates of Environmental Concern. Demographic correlates of these scores were then examined, using gender, age, political affiliation, income, education, and religious beliefs as grouping variables in a MANOVA with egoistic, altruistic, and biospheric attitudes as dependent variables. For gender, results showed women to score higher than men on all three measures of environmental concern $(F(3,999)=9-93$; Hotellings $=0-03 ; p<0-001)$. Age was negatively correlated with egoistic concerns $(r=-20 ; p<0-001)$, altruistic concerns $(r=-0$ 12; $p<0-001)$, and biosphericconcerns $(r=-0-10 ; p<0-001)$. Political affiliation, education and income were not significantly correlated with any of the three environmental concern scores. Examination of religion showed self-identified 'Catholics' to score higher on all three types of environmental concerns than 'Protestants' $(F(3,584)=8-08$; Hotellings $=0-04 ; p<0-001)$. No significant differences were found for respondents classified as Jewish, No Religion, Christian, or Other.

\section{Study 3}

The results from Studies 1 and 2 provide support for the distinction between egoistic, altruistic, and biospheric environmental concerns among college students and among the general population. In this third study, we examine the relationship between the three environmental concerns, several previously-published measures of environmental attitudes, self-reported proenvironmental behavior, empathy, social value orientation, and a modified Inclusion of Other in Self scale.

\section{Methodology}

Participants in the study were 148 U.S. undergraduates enrolled in psychology courses. Participants completed a packet of surveys to earn extra course credit.

Measures included:

(1) The 12 environmental concern items used in Study 1.

(2) The 15 -item revised version of the New Environmental Paradigm (Dunlap et al., 1992). The original 12 -item NEP scale (and the 15 -item revised version; Dunlap et al., 2000) measures the degree to which a person views humans as an integral part of the natural environment, rather than as separate from nature. Within this new paradigm, the earth's resources are viewed as limited, and the ecological balance is seen as fragile and easily disrupted by human behavior. Stern et al. (1995a) have suggested that the NEP measures an individual's general awareness of the consequences of harming the natural environment.

(3) The Interpersonal Reactivity Index (Davis, 1983, 1996). The IRI measures differences in the degree to which an individual is able to empathize with others. The scale is composed of four subscales. Perspective taking (PT) reflects a person's tendency to spontaneously take the perspective of another person in daily life. Empathic concern (EC) reflects a person's ability to have feelings of compassion and sympathy for unfortunate others. The personal 
distress (PD) scale measures the extent to which a person feels discomfort and distress in response to others who are in distress. Finally, the fantasy (FS) subscale measures the tendency to 'imaginatively transpose oneself into fictional situations' (Davis, 1996, p. 57).

(4) A measure of the perceived relationship between self and nature was created by adapting Aron et al., (1992) Inclusion of Other in Self (IOS) scale (see also Aron et al., 1991). Participants were asked to select from a series of seven overlapping circles labeled 'self' and 'nature.' The item read 'Please circle the picture that best describes your relationship with the natural environment. How interconnected are you with nature?' Scores ranged from 1 (where the circles touched but did not overlap) to 7 (where the circles were nearly entirely overlapping). We refer to this modified scale as the Inclusion of Nature in Self (INS) scale.

(5) The Social Value Orientation Scale (Van Lange et al., 1997; Van Vugt, 1997). The SVO is used to classify people based on 'stable preferences for certain patterns of outcomes for oneself and others.' Based on scale scores, respondents are classified as either prosocials, individualists, or competitors. Prosocials strive for equality, and tend to maximize outcomes for both themselves and others and to minimize differences between outcomes. Individualists maximize their own outcomes with little or no regard for others' outcomes. Competitors tend to maximize their own outcomes relative to others' outcomes. Joireman et al. (in press) report finding that participants classified as prosocials expressed stronger proenvironmental behavioral intentions than did participants classified as proself (i.e., individualists and competitors combined). See also Cameron et al. (1998).

(6) Proenvironmental behavior was measured using 12 items selected from past research (Schultz \& Zelezny, 1998). Each item asked respondents to report how frequently they had engaged in a series of specific behaviors (e.g., recycled newspaper, purchased products in a reusable or recyclable container, conserved gasoline by walking or bicycling). Each behavior was rated from 1 (never) to 5 (very often). A 'not applicable' response alternative was to provide exclude respondents who did not have access to certain programs. Not applicable responses were excluded when scale scores for proenvironmental behavior were calculated.

Scales were randomized within the packets to avoid order effects. Alpha reliabilities for the scales were acceptable. Alpha for the 15 -item NEP scale was 085 ; alpha reliability for the 15item proenvironmental behavior scale was $0-83$. Reliability coefficients for each of the fouritem environmental concern scales also showed acceptable reliability: Biospheric concerns (alpha $=0-92)$, altruistic concerns (alpha $=0-78)$, egoistic concerns (alpha $=0-83$ ). Alpha reliability for the four subscales of Interpersonal Reactivity Index scale were: Perspective taking ( 7 items) 0-79, empathic concern ( 7 items), personal distress (7 items) $0-79$, and fantasy (7 items) 0-75.

\section{Results}

Correlation coefficients were calculated between each of the measures, with the exception of the SVO scale which produces nominal data and was analysed separately. The resulting matrix is presented in Table 1 . As shown in the Table, biospheric concerns correlated positively with NEP $(r=0-48 ; p<0-001)$, the perspective taking $(r=0-27 ; p<0-001)$ and empathic concern $(r=$ $0-34 ; p<0-001)$ subscales of the Interpersonal Reactivity Index, the modified IOS scale $(r=0-31$; $p<0-001)$, and self-reported behavior $(r=0-31 ; p<0-001)$. Altruistic concerns correlated with the perspective taking $(r=0-30 ; p<0-001)$, empathic concern $(r=0-43 ; p<0-001)$, and personal distress $(r=0-23 ; p<0-01)$ subscales of the Interpersonal Reactivity Index. The table also shows the results for the 12-item proenvironmental behavior scale: results showed significant correlations with biospheric concerns $(r=0-31 ; p<0-001)$, NEP $(r=0-20 ; p<0-05)$, perspective 
taking ( $\mathrm{r}=0-31 ; \mathrm{p}<0-001)$, empathic concern $(\mathrm{r}=0-17 ; \mathrm{p}<0-05)$, and scores on the modified IOS scale $(r=0-41 ; p<0-001)$.

Additional analyses were performed on the Social Values Orientation. Of the 148 participants, 74 were classified as prosocial, 27 were classified as individualistic, 17 were classified as competitive, and 30 were not classifiable. Differences in environmental concerns between the three value types were assessed with a MANOVA using the SVO types as an independent variable, and biospheric, altruistic, and egoistic environmental concerns as dependent variables. The analysis revealed a significant omnibus effect $(F(6,216)=2-91 ; p<0-01$; Hotellings $=0-16)$. Follow-up univariate tests revealed a significant effect for egoistic concerns $(F(2,109)=4-95$; $p<0$ 001), but nonsignificant effects for altruistic $(F(2,109)=0-63)$ or biospheric $(F(2,109)=0$ $24)$ concerns. Tukey's HSD post hoc tests showed people classified as competitors $(M=6-18)$ and those classified as individualists ( $M=6-04)$, scored significantly higher on egoistic concerns than did people classified as prosocials $(M=5-27)$. Competitors and individualists did not differ significantly on egoistic concerns. Two similar one-way analyses were conducted using SVO types as the independent variable and NEP and environmental behavior scale scores as dependent variables. These analyses revealed no significant differences between the three SVO types.

TABLE 1

Correlation coefficients between measures of environmental concern, empathy, and selfreported behavior

\begin{tabular}{|c|c|c|c|c|c|c|c|c|c|c|}
\hline Scale & 1 & 2 & 3 & 4 & 5 & 6 & 7 & 8 & 9 & 10 \\
\hline $\begin{array}{r}\text { 1.Biospheric } \\
\text { concerns }\end{array}$ & $(0-92)$ & & & & & & & & & \\
\hline $\begin{array}{l}\text { 2.Altruistic } \\
\text { concerns }\end{array}$ & $0-32 * * *$ & $(0-78)$ & & & & & & & & \\
\hline 3.Egoistic concerns & $0-28 * * *$ & $0-44^{* * *}$ & $(0-83)$ & & & & & & & \\
\hline 4.NEP-Revised & $0-48^{* * *}$ & $0-05$ & $0-03$ & $(0-85)$ & & & & & & \\
\hline $\begin{array}{l}\text { 5.IRI-perspective } \\
\text { taking }\end{array}$ & $0-27^{* * *}$ & $0-30^{* * *}$ & $0-07$ & $0-16$ & $(0-79)$ & & & & & \\
\hline $\begin{array}{l}\text { 6.IRI-empathic } \\
\text { concern }\end{array}$ & $0-34^{* * *}$ & $0-43^{* * *}$ & $0-09$ & $0-21^{*}$ & $0-44^{* * *}$ & $(0-77)$ & & & & \\
\hline $\begin{array}{l}\text { 7.IRI-personal } \\
\text { distress }\end{array}$ & $-0-10$ & $0-23^{* *}$ & $-0-01$ & $-0-10$ & $-0-07$ & $0-13$ & $(0-79)$ & & & \\
\hline 8.IRI-fantasy & $0-15$ & $0-10$ & $-0-08$ & $0-11$ & $-0-03$ & $0-38^{* * *}$ & $0-24 * *$ & $(0-75)$ & & \\
\hline $\begin{array}{l}\text { 9.Inclusion of } \\
\text { Nature of Self } \\
\text { (INS) }\end{array}$ & $0-31^{* * *}$ & $0-18^{*}$ & $0-09$ & $0-20^{* *}$ & $0-30 * * *$ & $0-13$ & $-0-01$ & $0-17$ & $(\mathrm{NA})^{\tau}$ & \\
\hline $\begin{array}{l}\text { 10. Self-reported } \\
\text { behavior }\end{array}$ & $0-31^{* * *}$ & $0-08$ & $0-03$ & $0-20 *$ & $0-31^{* * *}$ & $0-17 *$ & $-0-10$ & $-0-02$ & $\begin{array}{l}0- \\
41^{* * *}\end{array}$ & $(0-83)$ \\
\hline
\end{tabular}

${ }^{\tau}$ The INS is a single-item measure Sample size $=148$

${ }^{*} p<0-05 ;{ }^{* *} p<0-01 ; * * * p<0-001$. 


\section{Study 4}

The results from the first three studies have shown an acceptable level of fit between the 12 selected attitude objects and the proposed three-factor model, and an interpretable pattern of relationships between our three measures of environmental concern, existing measures of environmental attitudes, empathy, and social value orientation. In this fourth study, we used data from a recent multi-national sample of Spanish-speaking college students. We predicted that although there may be country-level differences in mean scores for each of the three environmental concerns, the basic three-factor structure would hold across countries. Further, we examined the relationship between Schwartz's higher order values (Schwartz, 1992, 1994) and environ- mental concerns. We predicted that egoistic concerns would be positively correlated with self-enhancement, altruistic concerns would be positively correlated with conservation, and biospheric concerns would be positively correlated with selftranscendence. With the exception of our prediction that the conservation value would predict altruistic concerns, these predictions match those made by Stern et al. (1995b).

\section{Methodology}

The data for this study were collected as part of a multi-national study of environmental attitudes, funded by the Society for the Psychological Study of Social Issues (APA division 9). For other results based on this data set, see Schultz \& Zelezny (1999).

Participants. Participants in the study were social science students from colleges and universities in 10 countries in Latin America. Contacts for this study were university professors in Colombia, Costa Rica, El Salvador, the Dominican Republic, Ecuador, Pana- ma, Paraguay, Peru, Spain, and Venezuela. Contacts were mailed a packet of 100 to 200 surveys, and they then distributed them to their students. Data were obtained from Colombia $(n=149)$, Costa Rica $(n=213)$, the Dominican Republic $(n=121)$, Ecuador $(n=201)$, El Salvador $(n=194)$, Panama $(n=100)$, Paraguay $(n=200)$, Peru $(n=224)$, Spain $(n=104)$, and Venezuela $(n=194)$. A few smaller samples were obtained from Argentina, Canada, England, and Mexico, but these samples were excluded from this analysis because they had fewer than 100 cases.

\section{Materials.}

The survey contained the revised New Environmental Paradigm scale (Dunlap et al., 1992; Dunlap et al., 2001), Thompson and Barton's (1994) ecocentrism and anthropocentrism scales, Schwartz's $(1992,1994)$ value items, the 15 -item self-report proenvironmental behavior scale used in Study 2, and the 12 items from the environmental concern scale used in Study 1. The items were: marine life, birds, plants, animals, my children, people in my country, all people, children, my health, my future, my life- style, and me. The question wording is shown in Appendix 1. Our focus here is on the structure of environmental attitudes and the relationship between attitudes of concern and values.

Because of space constraints in the questionnaire, we did not use all 56 of Schwartz's items. Following Schultz and Zelezny (1998) we used 37 items. Items were selected based on the empirical locations of each value in regions generated from a series of smallest space analyses reported by Schwartz (1994). We selected the four items with the greatest frequency of occurrence in each of the 10 primary regions; the selected items were those that emerged most often in the appropriate value-type region in 97 independent samples from 44 countries. Each of the value-items was rated 'as a guiding principle in my life' from 0 (not important) to 7 (extreme importance). Values to which the respondent was opposed were scored-1. 
Procedure. Spanish versions of the items were produced through a back-translation procedure. The items were translated by two bilingual college students. The Spanish questionnaire was then back- translated by a third bilingual student, and the two English versions of the survey were compared. Discrepancies between any of the items were resolved by the three translators.

The Spanish survey was pilot tested with 15 fluent Spanish-speaking exchange students, and each pilot participant was encouraged to ask questions about items that were unclear. Finally, the Spanish survey was sent to each collaborator who was asked to make comments. The Spanish version of the egoistic, altruistic, and biospheric items is shown in Appendix 2.

Confirmatory factor analysis. Analyses were performed using Amos 4.0. Using a multi-group confirmatory factor analysis, the three-factor model was simultaneously fit to the covariance matrices of the ten samples. Because of the heterogeneous nature of the samples, our ambitious attempt to fit a model developed with U.S. respondents to samples from 10 different countries, and potential linguistic and response differences across Spanish-speaking countries, we adopted slightly less stringent cutoffs for an acceptable level of fit. Adopted limits were GFI >0-85, RMSEA $<0-15$, and TLI $>0-85$. These limits, although slightly lower than those adopted in Study 1 , seem reasonable given the diversity of the samples. The proposed 3 -factor mod- el was fit to the 10 samples: no other parameters were constrained, leaving the means, variances, item loadings, and factor correlations free to vary across the samples.

Analyses revealed that the independence model could be rejected (df. $=660 ; \chi^{2} / \mathrm{df} .=15-35$; GFI = 0-38; RMSEA =0-26; TLI =0-00). The 1-factor model showed an improved, but unacceptable fit (df. = 540; $\left.\chi^{2} / \mathrm{df} .=7-67 ; \mathrm{GFI}=0-68 ; \mathrm{RMSEA}=0-21 ; \mathrm{TLI}=0-4\right)$. The two-factor model was a significant improvement $\left(\chi^{2}(10)=1,926-40\right)$ over the one-factor model, and overall showed a marginal fit to the data (df. $=530 ; \chi^{2} /$ df. $=4-18$; GFI $=0-82$; RMSEA $=0-14$; TLI $=0-78$ ). Examination of the three-factor model showed a significant improvement $\left(\chi^{2}(20)=313-10 ; p<0\right.$ 001) and overall, an acceptable fit (df. = 510; $\chi^{2} / \mathrm{df} .=3-73$; GFI = 0-86; RMSEA = 0-11; TLI =081).

To generate model coefficients, a Confirmatory Factor Analysis was performed on the total sample, collapsing across the 10 groups $(n=1,700)$. Results showed an acceptable fit for the 3 factor model (df. $=51 ; \chi^{2}$ df. =12-87; GFI =0-94; RMSEA =0-08; TLI = 0-90). The standardized factor loadings are shown in Figure 2. Correlation coefficients between the three factors were 0 54 for biospheric and altruistic, 0-82 for altruistic and egoistic, and 0-40 for biospheric and egoistic. The correlation matrix for this combined sample is presented in Appendix 3.

Relationship between environmental concerns and values. Items from each of Schwartz's four higher- order values were averaged to produce scale scores, and reliability coefficients were calculated for each measure. Alpha reliability for self-transcendence (8 items) was 0-76; alpha reliability for self-enhancement (8 items) was 0 83; Alpha reliability for open- ness (9 items) was 0 71; alpha reliability for conservation (12 items) was 086. 


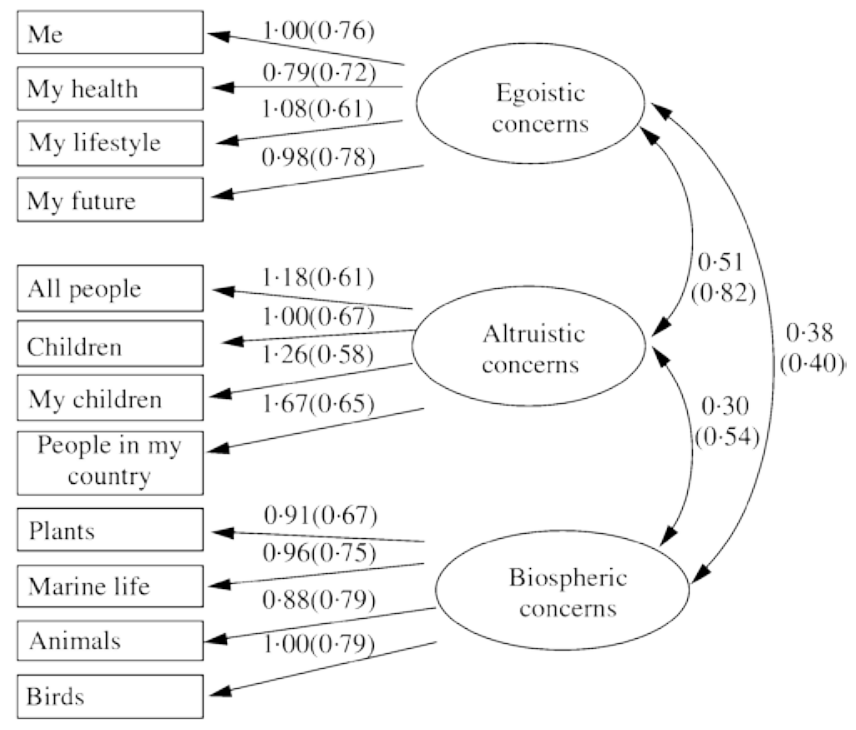

FIGURE 2. Results from a Confirmatory Factor Analysis of the Combined Cross-Cultural Sample

\section{TABLE 2}

Partial correlation coefficients between values and environmental concerns, controlling for the mean value rating

\begin{tabular}{|l|l|l|l|}
\hline & \multicolumn{3}{|c|}{ Environmental concerns } \\
\hline & Egoistic & Altruistic & Biospheric \\
\hline Value & $r$ & $r$ & $r$ \\
\hline Self-transcendence & $-0-06^{*}$ & $0-10^{* *}$ & $0-29 * * *$ \\
\hline Self-enhancement & $0-18^{* * *}$ & $-0-13^{* * *}$ & $-0-28 * * *$ \\
\hline Openness & $-0-04$ & $0-00$ & $0-04$ \\
\hline Conservation & $0-01$ & $-0-07$ & $-0-08$ \\
\hline
\end{tabular}

${ }^{*} \mathrm{p}<005 ; * * \mathrm{p}<001 ; * * * \mathrm{p}<0001$ $\mathrm{n}=1,700$.

Correlation coefficients were calculated between egoistic, altruistic, and biospheric environmental concerns, and the four higher order values. Because the environmental concerns have been shown to generalize across countries, and Schwartz's values are considered to be universal, analyses were not performed separately by country. To control for individual differences in the use of the values response scale and also to control for acquiescence bias and differences in the use of the response categories across countries, each person's mean value rating was used as a covariate. Mean value ratings were produced by averaging the responses to all 37 of the value items used in the questionnaire. 
TABLE 3

Concern of environmental issues: mean scores across samples

\begin{tabular}{|l|l|l|l|l|l|l|}
\hline Sample & Egoistic & (S.D.) & Altruistic & (S.D.) & Biospheric & (S.D.) \\
\hline $\begin{array}{l}\text { US College Students } \\
(n=148)\end{array}$ & $5-67$ & $(1-41)$ & $5-89$ & $(1-25)$ & $5-33$ & $(1-46)$ \\
\hline $\begin{array}{l}\text { US College Students } \\
(n=1,010)\end{array}$ & $5-47$ & $(1-51)$ & $5-78$ & $(1-49)$ & $5-33$ & $(1-38)$ \\
\hline $\begin{array}{l}\text { California General } \\
\text { Sample }(n=1,005)\end{array}$ & $5-48$ & $(1-55)$ & $5-84$ & $(1-43)$ & $5-46$ & $(1-49)$ \\
\hline Colombia $(n=148)$ & $6-01$ & $(1-23)$ & $6-16$ & $(0-96)$ & $6-24$ & $(0-93)$ \\
\hline Costa Rica $(n=213)$ & $5-94$ & $(1-14)$ & $6-34$ & $(0-87)$ & $6-31$ & $(0-87)$ \\
\hline El Salvador $(n=194)$ & $6-15$ & $(1-09)$ & $6-36$ & $(0-98)$ & $6-53$ & $(0-88)$ \\
\hline $\begin{array}{l}\text { Dominican Republic } \\
(n=121)\end{array}$ & $6-30$ & $(0-82)$ & $6-43$ & $(0-71)$ & $6-28$ & $(0-64)$ \\
\hline Ecudaor $(n=201)$ & $6-16$ & $(0-91)$ & $6-41$ & $(0-66)$ & $6-26$ & $(0-81)$ \\
\hline Panama $(n=100)$ & $6-32$ & $(0-96)$ & $6-45$ & $(0-87)$ & $6-17$ & $(1-05)$ \\
\hline Paraguay $(n=200)$ & $5-88$ & $(1-09)$ & $6-28$ & $(0-91)$ & $6-19$ & $(0-94)$ \\
\hline Peru $(n=224)$ & $5-83$ & $(1-14)$ & $6-03$ & $(1-02)$ & $5-57$ & $(1-15)$ \\
\hline Spain $(n=104)$ & $5-92$ & $(1-32)$ & $6-33$ & $(0-96)$ & $5-83$ & $(1-10)$ \\
\hline Venezuela $(n=194)$ & $6-16$ & $(1-14)$ & $6-38$ & $(0-82)$ & $6-26$ & $(0-84)$ \\
\hline
\end{tabular}

Partial correlation coefficients were calculated between each of the higher order values and environmental concern, controlling for the mean value response. These partial coefficients are shown in Table 2. The results from these analyses show a clear pattern of values differentiating egoistic from biospheric concerns. Self-enhancement correlated positively with egoistic $(r=0$ 18; $p<0-001)$, negatively with altruistic $(r=-0-13 ; p<0-001)$, and negatively with biospheric $(r$ $=-0-28 ; p<0-001)$ environmental concern. In contrast, self-transcendence correlated positively with biospheric ( $r=0-29 ; p<0-001)$, positively with altruistic $(r=0-10 ; p<0-01)$, and negatively with egoistic $(r=-0-06 ; p<0-05)$ environmental concerns. Contrary to our prediction, conservation was negatively correlated with biospheric $(r=-0-08 ; p<0-05)$ and altruistic $(r=-0$ $07 ; p<0-05)$ concerns.

Mean scores for egoistic, altruistic, and biospheric concerns across the 10 samples reported in Study 4, along with the scores for the three U.S. samples reported in Studies 1, 2, and 3, are presented in Table 3.

\section{Discussion}

The results from these studies provide solid empirical evidence for a tripartite classification of environ- mental concerns. Based on previous research, we predicted that concerns for the consequences of environmental damage would form three correlated factors organized around self, other people, and the biosphere. Our results showed that this three-factor model provided an acceptable fit among a range of diverse samples: U.S. college students, a sample of the general public, and among samples of college students from 10 countries.

So why do environmental concerns form three correlated factors? One possible explanation comes from Stern and Dietz's (1994) value basis theory. The value-basis theory suggests that attitudes about environmental issues are the result of more general underlying values, and that different value orientations lead to different attitudes. In addition, the link between values and environmental concern is moderated by an awareness of the harmful consequences to valued 
objects. 'The key elements of our model are broad value orientations and beliefs about the effects of particular attitude objects on those values' (Stern et al., 1995b, p. 1615). From this perspective, the three clusters of environmental concerns identified in the studies above are the direct result of values-valuing self, other people, or the biosphere.

Our results are consistent with this interpretation. The strongest support comes from Study 4, which showed that egoistic and biospheric environmental concerns were related to different values. Using items from Schwartz's (1992, 1994) values scale, we found egoistic concerns to be positively correlated with self-enhancement and negatively with self-transcendence. In contrast, biospheric concerns were negatively correlated with self-enhancement and positively correlated with self-transcendence (see Schultz \&Zelezny, 1999 for similar findings). The valuebasis for altruistic concerns appears to be similar to that found for biospheric concerns: altruistic concerns were negative correlated with self-enhancement and positively correlated with selftranscendence. This finding replicates that of Stern et al. (1995b). Additional evidence for a value-basis interpretation comes from Study 2. Using the Social Value Orientations scale, results showed that individualists and competitors (i.e., proselfs) scored significantly higher on egoistic environmental concerns than did people with a pro- social value orientation.

In essence, the value-basis theory does a nice job of explaining the findings reported in this paper. However, we go one step further. We propose that objects (e.g., plants, animals, other people) are valued because of the degree to which they are included within an individual's cognitive representation of self (Schultz, 2000; Schultz \& Zelezny, 1999). This interpretation is consistent with several other areas of social psychological research (e.g., Aron et al., 1991; Batson, 1994; Cialdini et al., 1997). Several findings from the current study lend support to this explanation. First, using a modified version of the Inclusion of Other in Self (IOS) scale in Study 3 , we found a positive relationship between ratings of the 'interconnectedness' of self and nature and biospheric environmental concerns $(r=0-31)$. Aron et al. (1991) and Aron \& Fraley (1999) have argued that close relationships are characterized by an 'inclusion' or overlapping of selfschemas with schemas of another person. 'The basic elements of interpersonal closeness is cognitive, an overlap of knowledge structures of self and other, such that in a close relationship each individual includes aspects of the other as part of his or her notion of self' (Aron \& Fraley, 1999, p. 141). Our adaptation of the IOS scale to measure Inclusion of Nature in Self (INS) shows a similar inclusion between self and nature (see also Brown \& Schultz, 2000).

Second, results from Study 3 showed a positive correlation between the perspective taking and empathic concern subscales of the Interpersonal Reactivity Index (IRI) and both biospheric and altruistic environmental concerns. There is a sizeable volume of research on perspective taking, its relationship to empathy, and its effects on prosocial behavior ( $c f$. Davis, 1996). The perspective taking subscale of the IRI measures the tendency to adopt the psychological point of view of others. Previous research has shown that taking another's point of view can lead to a greater degree of other-inclusion in self (Davis et al., 1996). That is, taking the perspective of an- other person can expand our boundaries of self to include others. Preliminary findings by Schultz (2000) suggest that experimentally-induced perspective taking produced increases inbiospheric environmental concerns.

Our interpretation - that the reported results reflect varying levels of a perceived interconnection between self and nature-is also consistent with the findings in Study 4. Results showed that biospheric concerns correlated positively with self-transcendence and negatively with self-enhancement. Schultz and Zelezny (1999) have suggested that selftranscendence reflects the degree to which a person values goals and ideals that are not directly linked to self (e.g., broad-minded, a world of beauty, loyal, honest, forgiving), while self-enhancement reflects the degree to which a person values goals and ideals that are directly linked with tangible rewards for self (e.g., successful, ambitious, wealth, social power). We 
propose that self-enhancement reflects a general orientation toward self-benefit and that people who score high on self-enhancement do not define other people or other living things within their boundary of self. In contrast, self-transcendence reflects the degree to which a person includes other people and other living things within their notion of self. Our finding that altruistic concern did not correlate as strongly with self-transcendence (positively) or selfenhancement (negatively) as did biospheric concerns suggests that altruistic concerns may reflect an intermediate level of inclusion.

The argument that different types of environmental concern result from the degree to which an individual perceive an interconnection between self and nature resonates with several recent environmental texts. For example, in his discussion of the growing level environmental degradation worldwide, Hertsgaard (1999) states, 'Many Americans and Europeans, especially those living in cities, have grown so distanced from the natural world that they seem to think they could live without it' (p. 25). Thus, we might predict that people living in large cities (e.g., Mexico City, Los Angeles, New York City, Bankok) would perceive less interconnection between self and nature, and subsequently tend to develop egoistic environmental concerns. Numerous other authors have written about an individual's 'relationship' or 'connection with' the natural environment (cf. Bragg, 1996; Kinder, 2001; Weigert, 1997).

To conclude, the four studies presented in this paper provide strong evidence for the tripartite classification of environmental concerns organized around concern for self, other people, or the bio- sphere. Among several diverse samples, our findings indicate that concerns about the harmful 
consequences of environmental damage form three correlated clusters, which represent harmful consequences for self, other people, and plants and animals. We have interpreted these results within a broad social-cognitive theory and suggested that the type of concerns an individual develops is based on the degree to which they perceive an interconnection between themselves and other people (altruistic), or between themselves and nature (biospheric).

\section{Note}

Funding for the studies reported in this paper was provided by the Social Science and Instructional Council Faculty Fellowship (Study 2), and the Society for the Psychological Study of Social Issues (Study 4). I would like to acknowledge Pamela Brown and Karen Roslie for their work on Study 3. I would also like to acknowledge Lynnette Zelezny, her research group at CSU Fresno, and our international collaborators for their help with Study 4.

Correspondence and reprint requests should be ad- dressed to: Wesley Schultz, Department of Psychology, California State University, San Marcos, CA 92096, E-mail: psch@csusm.edu 


\section{References}

Arbuckle, J. A. (1997). Amos Users' Guide Version 3.6.Chicago, IL: SmallWaters.

Aron, A. \& Fraley, B. (1999). Relationship closeness as including other in the self: Cognitive underpinnings and measures. Social Cognition, 17, 140-160.

Aron, A., Aron, E. N. \& Smollan, D. (1992). Inclusion of other in the self scale and the structure of interpersonal closeness. Journal of Personality and Social Psychology, 63, 596-612.

Aron, A., Aron, E. N., Tudor, M. \& Nelson, G. (1991). Close relationships as including other in the self. Journal of Personality and Social Psychology, 60, 241-253.

Batson, C. D. (1994). Why act for the public good? Four answers. Personality and Social Psychology Bulletin, 20, 603-610.

Batson, C. D., Batson, J., Todd, R. M., Brummett, B. H., Shaw, L. L. \& Aldeguer, C. M. R. (1995). Empathy and the collective good: Caring for one of the others in a social dilemma. Journal of Personality and Social Psychology, 68, 619-631.

Bentler, P. M. (1990). Comparative fit indices in structural models. Psychological Bulletin, 107, 238-246.

Bollen, K. A. (1989). Structural Equations with Latent Variables. New York: Wiley.

Bosso, C. (1994). After the movement: Environmental activism in the 1990s. In N. Vig \& M. Kraft (Eds), Environmental Policy in the 1990s. Washington, DC: CQ Press.

Bragg, E. A. (1996). Towards ecological self: Deep ecology meets constructionist self-theory. Journal of Environ- mental Psychology, 16, 93-108.

Brown, P. L. \& Schultz, P. W. (2000). Cognitive representations of self and nature. Paper presented at the Western Psychological Association, Irvine, CA.

Cameron, L. D., Brown, P. M. \& Chapman, J. G. (1998). Social value orientation and decisions to take proenvironmental action. Journal of Applied Social Psychology, 28, 675-697.

Cialdini, R. B., Brown, S. L., Lewis, B. P., Luce, C. \& Neuberg, S. L. (1997). Reinterpreting the empathy-altruism relationship: When one into one equals oneness. Journal of Personality and Social Psychology, 73, 481-494.

Cudeck, R. \& Browne, M. W. (1983). Cross-validation of covariance structures. Multivariate Behavioral Research, 18, 147-167.

Davis, M. H. (1983). Measuring individual differences in empathy: Evidence for a multidimensional approach. Journal of Personality, 51, 167-184.

Davis, M. H. (1996). Empathy: A Social Psychological Approach. Boulder, CO: Westview. Davis, M. H., Conklin, L., Smith, A. \& Luce, C. (1996). Effect of perspective taking on the cognitive representation of persons: A merging of self and other. Journal of Personality and Social Psychology, 70, 713-726.

Dunlap, R. E. (1991). Trends in public opinion toward environmental issues: 1965-1990. Society and Natural Resources, 4, 285-312.

Dunlap, R. E. \& Van Liere, K. (1978). The new environmental paradigm. Journal of Environmental Education, 9, 10-19.

Dunlap, R. E., Gallup, G.\& Gallup, A. (1993). Global environmental concern: Results from an inter- national pubic opinion survey. Environment, 35, 7-15, 33-39.

Dunlap, R., Van Liere, K., Mertig, A. \& Howell, R. (1992, August). Measuring Endorsement of an Ecological Worldview: A Revised NEP Scale. Paper presented in the Annual Meeting of the Rural Sociology Society, PA.

Dunlap, R. E., Van Liere, K., Mertig, A. \& Jones, R. E. (2000). Measuring endorsement of the New Ecological Paradigm: A revised NEP scale. Journal of Social Issues, 56, 425-442.

Eagly, A. H. \& Chaiken, S. (1993). The Psychology of Attitudes. Fort Worth, TX: Harcourt Brace Jovanovich.

Gorsuch, R. L. (1983). Factor Analysis (2nd ed.). Hillsdale, NJ: Lawrence Erlbaum. 
Heberlein, T. A. (1971). Environmental attitudes. Zeitschrift fur Umweltpolitik, 2, 241-270.

Hertsgaard, M. (1999). Earth Odyssey: Around the World in Search of Our Environmental Future. New York: Broadway Books.

Joireman, J. A., Lasane, T. P., Bennett, J., Richards, D. \& Solaimani, S. (in press). Integrating social value orientation and the consideration of future consequences within the extended norm activation model of proenvironmental behavior. British Journal of Social Psychology.

Kaplan, D. (2000). Structural Equation Modeling: Foundations and Extensions. Thousand Oaks, CA: Sage.

Kempton, W., Boster, J. \& Hartley, J. (1995). Environmental Values in American Culture. Cambridge, MA: MIT Press.

Kinder, D. (2001). Nature and Psyche: Radical Environmentalism and the Politics of Subjectivity. New York: State University of New York Press.

Lounsbury, J. \& Tornatzky, L. G. (1977). A scale for assessing attitudes toward environmental quality. Journal of Social Psychology, 101, 299-305.

Maloney, M. P. \& Ward, M. P. (1973). Ecology: Let’s hear from the people. An objective scale for the measure- ment of ecological attitudes and knowledge. American Psychologist, 28, 583-586.

Maloney, M. P., Ward, M. P. \& Braucht, G. N. (1975). A revised scale for the measurement of ecological attitudes and knowledge. American Psychologist, 30, 787-790.

Maruyama, G. M. (1998). Basics of Structural Equation Modeling. Thousand Oaks, CA: Sage.

Olsen, M. E. (1981). Consumers' attitudes toward energy consumption. Journal of Social Issues, 37, 108-131.

Schultz, P. W. \& Zelezny, L. (1998). Values and proenvironmental behavior: A five-country survey. Journal of Cross-Cultural Psychology, 29, 540-558.

Schultz, P. W. \& Zelezny, L. C. (1999). Values as predictors of environmental attitudes: Evidence for consistency across cultures. Journal of Environmental Psychology, 19, 255-265.

Schultz, P. W. (2000). Empathizing with nature: Toward a social-cognitive theory of environmental concern. Journal of Social Issues, 56, 391-406.

Schwartz, S. H. (1977). Normative influences on altruism. In L. Berkowitz (Ed.), Advances in Experimental Social Psychology (Vol. 10, pp. 221^279). New York: Academic.

Schwartz, S. H. (1992). Universals in the content and structure of values: Theoretical advances and empirical tests in 20 countries. In M. Zanna (Ed.), Advances in Experimental Social Psychology (Vol. 25, pp. 1-65). Orlando, FL: Academic.

Schwartz, S. H. (1994). Are there universal aspects in the structure and contents of human values? Journal of Social Issues, 50, 19-45.

Stern, P. C. \& Dietz, T. (1994). The value basis of environmental concern. Journal of Social Issues, 50, 65-84.

Stern, P. C., Dietz, T. \& Kalof, L. (1993). Value orientations, gender, and environmental concern. Environment and Behavior, 25, 322-348.

Stern, P. C., Dietz, T. \& Guagnano, G. A. (1995a). The new ecological paradigm in socialpsychological context. Environment and Behavior, 27, 723-744.

Stern, P. C., Dietz, T., Kalof, L. \& Guagnano, G. A. (1995b). Values, beliefs, and proenvironmental action: Attitude formation toward emergent attitude objects. Journal of Applied Social Psychology, 25, 1611-1636.

Stern, P. C. \& Oskamp, S. (1987). Managing scarce environmental resources. In D. Stokols and I. Altman (Eds), Handbook of Environmental Psychology. New York: Wiley.

Thompson, S. C. G. \& Barton, M. A. (1994). Ecocentric and anthropocentric attitudes toward the environment. Journal of Journal of Environmental Psychology, 14, 149-157.

Van Lange, P., DeBruin, E., Otten, W. \& Joireman, J. A. (1997). Development of prosocial, 
individualistic, and competitive orientations: Theory and preliminary evidence. Journal of Personality and Social Psychology, 73, 733-746.

Van Vugt, M. (1997). Concerns about the privatization of public goods: A social dilemma analysis. Social Psychology Quarterly, 60, 355-367.

Weigel, R. H. (1983). Environmental attitudes and the prediction of behavior. In N. R. Feimer and E. S. Geller (Eds), Environmental Psychology: Directions and Perspectives. New York: Praeger. Weigel, R. H. \& Weigel, J. (1978). Environmental concern: the development of a measure. Environment and Behavior, 10, 3-15.

Weigert, A. J. (1997). Self, Interaction, and Natural Environment: Refocusing our Eyesight. New York: State University of New York Press.

\section{Appendix 1}

Measuring environmental motives: items in English

People around the world are generally concerned about environmental problems because of the consequences that result from harming nature. However, people differ in the consequences that concern them the most. Please rate each of the following items from 1 (not important) to 7 (supreme importance) in response to the question:

\begin{tabular}{|l|l|l|}
\hline \multicolumn{2}{|l|}{ I am concerned about environmental problems because of the consequences for --. } \\
\hline-- Plants & -- Me & -- People in my country* \\
\hline-- Marine life & -- My lifestyle & -- All people \\
\hline -- Birds & -- My health & -- Children \\
\hline-- Animals & -- My future & -- My children ${ }^{1}$ \\
\hline
\end{tabular}

*An alternative wording is 'People in the community'

${ }^{1}$ An alternative wording is 'Future generations.'

\section{Appendix 2}

Measuring environmental motives: items in Spanish

Generalmente, la gente de todas partes del mundo se preocupa sobre los problemas ambientales causados por la explotación de la naturaleza. Sin embargo, hay opiniones diferentes sobre cuáles consecuencias tienen la mayor importancia. Por favor, califique los temas siguientes. Use la escala de 7 puntos, 1 (ninguna importancia) a 7 (máxima importancia), para responder a cada pregunta.

\begin{tabular}{|l|l|l|}
\hline Estoy preocupado(a) sobre los problemas ambientales que tienen consecuencias sobre -- \\
\hline-- Plantas & -- Yo & -- Mis paisanos \\
\hline -- Vida acuática & -- Mi estilo de vida & -- Toda la gente \\
\hline -- Aves & -- Mi salud & -- Niños \\
\hline-- Animales & -- Mi futuro & -- Mis hijos \\
\hline
\end{tabular}




\section{Appendix 3}

Correlation matrix for the 12 environmental concern items reported in study 4

\begin{tabular}{|l|l|l|l|l|l|l|l|l|l|l|l|l|}
\hline Item & 1 & 2 & 3 & 4 & 5 & 6 & 7 & 8 & 9 & 10 & 11 & 12 \\
\hline 1. Marine Life & $(1-21)$ & & & & & & & & & & & \\
\hline 2. Birds & $0-60$ & $(1-19)$ & & & & & & & & & & \\
\hline 3. Plants & $0-51$ & $0-55$ & $(1-27)$ & & & & & & & & & \\
\hline 4. Animals & $0-58$ & $0-62$ & $0-53$ & $(1-05)$ & & & & & & & & \\
\hline 5. My Children & $0-21$ & $0-16$ & $0-12$ & $0-21$ & $(-18)$ & & & & & & & \\
\hline $\begin{array}{l}\text { 6. People in my } \\
\text { Community }\end{array}$ & $0-28$ & $0-26$ & $0-21$ & $0-30$ & $0-35$ & $(1-55)$ & & & & & & \\
\hline 7. All people & $0-22$ & $0-24$ & $0-21$ & $0-34$ & $0-40$ & $0-38$ & $(1-18)$ & & & & & \\
\hline 8. Children & $0-28$ & $0-26$ & $0-20$ & $0-38$ & $0-42$ & $0-38$ & $0-42$ & $(0-94)$ & & & & \\
\hline 9. My Health & $0-21$ & $0-25$ & $0-15$ & $0-34$ & $0-36$ & $0-35$ & $0-32$ & $0-47$ & $(1-12)$ & & & \\
\hline $\begin{array}{l}\text { 10. My future } \\
\text { 11. My } \\
\text { Lifestyle }\end{array}$ & $0-21$ & $0-25$ & $0-15$ & $0-30$ & $0-33$ & $0-44$ & $0-30$ & $0-36$ & $0-58$ & $(1-29)$ & & \\
\hline \begin{tabular}{l} 
12. Me \\
\hline
\end{tabular} & $0-17$ & $0-21$ & $0-14$ & $0-21$ & $0-20$ & $0-54$ & $0-23$ & $0-27$ & $0-42$ & $0-50$ & $(1-80)$ & \\
\hline
\end{tabular}

Sample size $=1700$

Note: Standard deviations for each item are shown in parentheses. 